\title{
Permanence of Glass Standards of Spectral Transmittance
}

\author{
By Kasson S. Gibson and Marion A. Belknap
}

\begin{abstract}
Shortly after the introduction of commercially available photoelectric spectrophotometers, the National Bureau of Standards began issuing calibrated disks for checking the photometric scale of spectrophotometers. At the time these standards were selected no precise information was available regarding their permanence. The present paper presents data showing that the glass standards kept in the files for 16 years with only occasional use have not changed. Data are also given showing the nature of the changes occurring in glasses similar to the standards when exposed under glass to south skylight (including sunlight) for periods up to 3 years.
\end{abstract}

\section{Introduction}

One of the essential parts of a spectrophotometer is the photometric equipment, and the accuracy of the photometric scale is one of the major items with which both the manufacturer and the user of the spectrophotometer should be concerned. This photometric scale may be based on optical principles and devices, as in all visual spectrophotometers and the Hardy or General Electric recording spectrophotometer, or it may be based on electrical principles and devices, as in many of the other photoelectric spectrophotometers. Whatever the method, the user of the spectrophotometer should have some means available to insure that the instrument is giving reliable results or to warn him that something is wrong.

On a visual spectrophotometer this can be done by means of rapidly rotating sectored disks, whose apertures can be mechanically calibrated with high accuracy. On photoelectric spectrophotometers, however, for one reason or another, such a procedure is not generally feasible. An acceptable alternative, and one that is in general much more convenient, is the use of solutions or glass disks whose spectral transmissive properties are accurately known over the desired spectral range.

At first thought one might wish for a series of filters whose respective transmittances do not vary with wavelength, which will not displace the beam, which do not reflect strongly, and for which the transmittances can be independently determined with high accuracy. Such filters would enable a test of the photometric scale to be made that would be independent of all other sources of error, and if available they would probably be useful. They are not available, however, and in fact would probably not be as useful as the series of moderately selective filters that are discussed in the present paper. This is because the nonselective filters would not enable the detection of wavelength errors no matter how great; they would give no information regarding the effects of wide slits; nor would they detect the presence of stray spectral energy. The selective filters, on the other hand, will often yield valuable information about these things in addition to affording the desired check of the photometric scale over most of its range.

Shortly after the appearance of commercially available photoelectric spectrophotometers in 1930, this Bureau began the preparation and issuance of glass standards of spectral transmittance. These were described at a meeting of the Optical Society of America in 1933 [1]. ${ }^{1}$ They have been noted in other Bureau publications since that date $[2,3,4]$, and they have been listed in past and present Bureau test fee schedules. To date about 170 of these filters have been issued. ${ }^{2}$

\footnotetext{
1 Figures in brackets indicate the literature references at the end of this paper.

2 Solution standards of spectral transmittancy are described, with data. in NBS Letter Circular LC929 [3] and in NBS Circular C484 [4].
} 
At the time that decision was made on the types of filters to use, little quantitative information was available as to the permanence of colored glasses. Manganese glasses were known to be unstable, and the spectral transmittances of many glasses were known to vary in the ultraviolet upon exposure to strong ultraviolet radiant flux. On the other hand it can be assumed that many kinds of colored glass have high stability in the visible spectrum, else cathedral windows would have paled or otherwise deteriorated to a notable degree through the centuries of exposure.

Since no evidence was available that the common types of colored glass other than manganese would change, the selection of the filters was made wholly from the standpoint of suitable spectral transmittances in suitable thicknesses. Of necessity it was assumed that these glasses would remain constant until sufficient time had elapsed that changes could be ascertained even though small. The kinds of glass selected are described in the next section. For each type two glasses were selected for initial measurement, and these have been kept in the Bureau files, unused except for occasional measurement. These remeasurements were not systematic but were sufficient to show that no important changes were taking place.

Naturally there were often differences in the third decimal between the original and the repeat values of transmittance, but these were usually slight and always within the combined experimental uncertainties. Nevertheless, consideration of these small differences made it seem desirable to carry out some kind of accelerated exposure test in order to find out the nature of any real changes that might be expected. This was accordingly carried out over a 3-year period.

The purpose of the present paper is to show the nature and extent of the changes produced under this accelerated exposure and to indicate the degree of certainty within which the Bureau standards (not so exposed) have or have not changed. It is believed that this information will be of interest to most of the users of these standards.

\section{The Standards}

\section{Description}

Four types of glass were finally chosen for these standards: (1) A "cobalt blue" glass from the
Corning Glass Works, designated by them formerly as G55A and at present as 5551. This has been used mostly in 3-mm thickness. (2) A "carbon yellow" glass from the Corning Glass Works, designated by them formerly as HT (high transmission) Yellow, and at present carrying their number 3307. This has been used mostly in 2-mm thickness. (3) A Jena "copper green" glass, supplied by the Fish-Schurman Corporation, and carrying the Jena number BG14. This has been used mostly in 2-mm thickness. (4) A Jena "selenium orange" glass, supplied by the Fish-Schurman Corporation, and carrying the Jena number OG3. This has also been used mostly in 2-mm thickness.

When it is desired not to be specific, these glasses will be referred to by the color names given above, but without quotes - namely, cobalt blue, carbon yellow, copper green, and selenium orange.

The usual procedure in preparing the standards has been to secure a supply of each kind of glass (all pieces from the same melt) and prepare as many disks (29.8 $\mathrm{mm}$ in diameter) as possible from the supply at hand. From these disks one or two would be selected and retained as Bureau standards. The others would be kept as standards to be issued. In this paper reference may be made to the "Bureau standards" or the "issued standards" where it is desired to differentiate between them, or simply to the "standards" or to the "glasses" if such differentiation is unimportant.

The general types of transmittance curves for these glasses are shown in figure 1. For each type are shown curves for the pair of glasses originally selected as Bureau standards in 1933 and a third curve for the Bureau standard selected from the glasses now being used. In general, the spectral transmittances of the issued standards are similar to but not identical with the values. illustrated in figure 1. The broken-line curves, below 390 and above $750 \mathrm{~m} \mu$, show the spectral transmittances of these glasses in the ultraviolet and near infrared, when these have been measured.

The wavelengths used in reporting values of transmittance for these standards (shown in table 1) are often the wavelengths of lines in the mercury or helium spectra. These were chosen originally with the intention of making the photometric measurements at these wavelengths with 


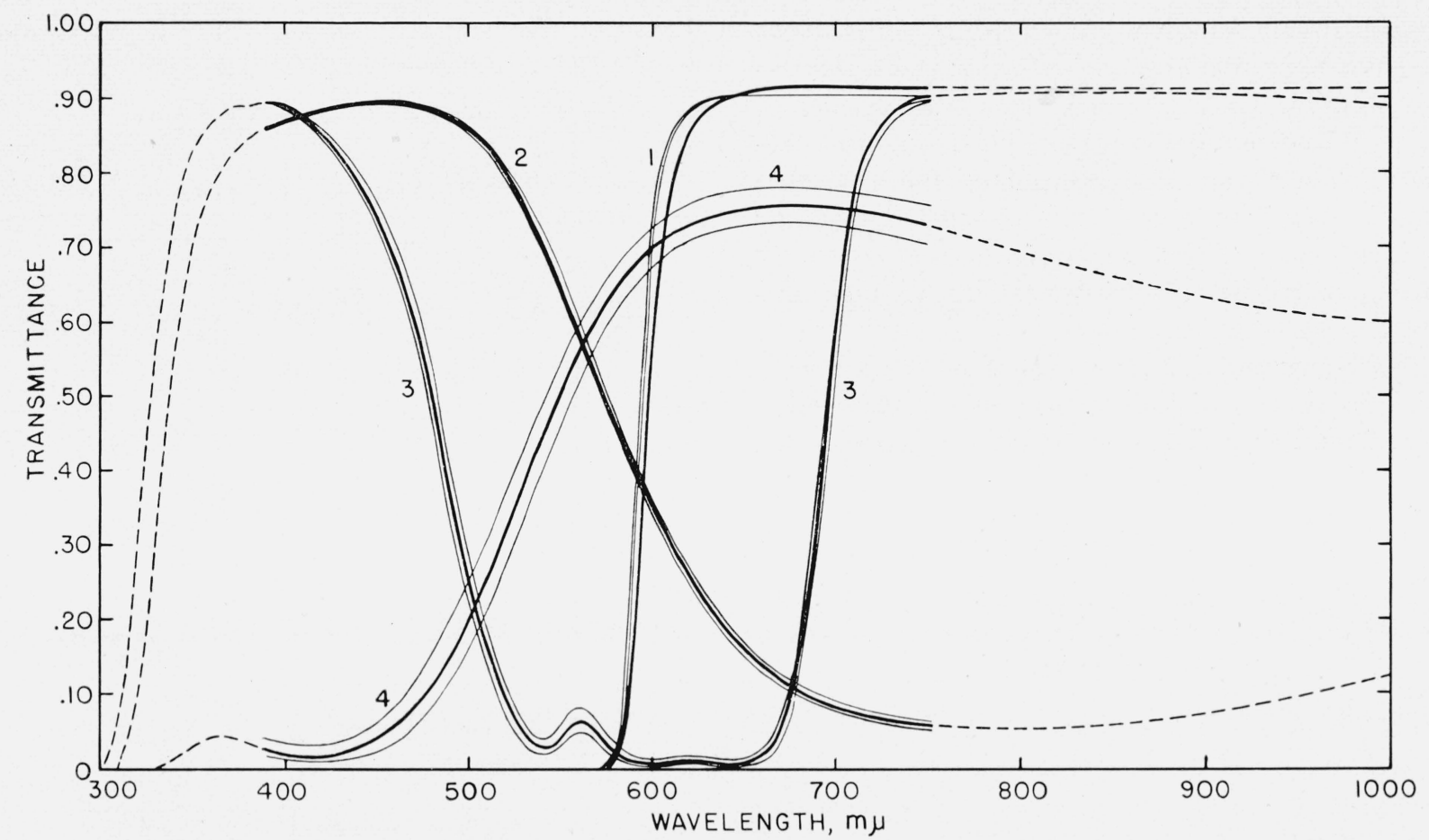

FIGURE 1. Spectral transmittances of the four types of glass standards: 1, selenium orange; 2, copper green; 3, cobalt blue; 4, carbon yellow

Light lines: standards of different thickness prepared in 1933. Heavy lines: standards now in use. The standards are issued primarily for the range 390 to $750 \mathrm{~m} \mu$. The broken lines show the ultraviolet and near infrared spectral transmittances of the present standards.

these sources, and the $\mathrm{Hg} 404.7,435.8,546.1$, and 578.0 (577.0 and 579.1 doublet) lines and the He 501.6 and 587.6 lines have been extensively used for such purpose. The advantage of this, as often pointed out, is that values are obtained that are independent of any possible wavelength and slitwidth errors. After extensive trial it was found, however, that the intensities at the other $\mathrm{Hg}$ and $\mathrm{He}$ wavelengths were so low that accuracy was lost rather than gained by their use. Although incandescent sources are now used at most of these other wavelengths in the standardization measurements, there is still some advantage in retaining these wavelengths instead of going to an adjacent even number (for example, 471.3 instead of 470) because of slightly greater certainty possible in wavelength calibrations. Furthermore, much of the value of earlier work at these $\mathrm{Hg}$ and $\mathrm{He}$ wavelengths would have been lost by starting anew at an adjacent wavelength.

\section{Temperature Effects}

It is probable that the spectral transmittance of all glasses changes at all wavelengths if the tem- perature change is sufficiently large (for example, from $-180^{\circ} \mathrm{C}$ to $+450^{\circ} \mathrm{C}$ ). Illustrations of such changes for a considerable number of types of glasses have been collected and published in NBS Circular 484 [4]. In many instances such changes are important even for the usual room temperature variations. For use as a standard of spectral transmittance, accordingly, it is necessary that the values be obtained and certified for some selected temperature and that a formula be given enabling the user of the glass to compute the spectral transmittance of the glass at room or instrument temperatures other than that specified.

Room temperatures in laboratories, if not airconditioned, often vary from around $20^{\circ} \mathrm{C}$ on winter mornings to above $30^{\circ} \mathrm{C}$ in summer weather. A temperature of $25^{\circ} \mathrm{C}$ was therefore selected as the most useful temperature for the standardization measurements, and the spectral transmittances of all issued standards are certified at this temperature.

In addition measurements were made at $40^{\circ} \mathrm{C}$ on the Bureau standards in 1933 and at $55^{\circ} \mathrm{C}$ on three of the four newly selected Bureau stand. 
ards in 1946. These more recent measurements were not only made at about twice the temperature interval used in the former measurements, but were also made with greater instrumental precision. They were thus considered more reliable than the earlier ones and have superseded them for certificate use. The two sets of values were wholly consistent within the uncertainties of measurement.

As already noted, at the start of the work standards of different thicknesses were used. A suitable way of reporting these temperature "coefficients", $d$, was therefore taken simply from the relations:

$$
\begin{aligned}
& -\log _{10} T_{25}=b a_{25}+k \\
& -\log _{10} T_{40}=b a_{40}+k \\
& -\log _{10} T_{\theta}=b a_{\theta}+k,
\end{aligned}
$$

where $T$ is the transmittance at the subscript temperature, $a$ is the absorbance index [5], $b$ is the thickness in millimeters, and $k$ is a constant (=- $\log _{10} 0.92$, approximately).

We define $d$ as equal to

$$
a_{40}-a_{25}=\frac{-\log _{10} T_{40}-\left(-\log _{10} T_{25}\right)}{b}
$$

and assume that

$$
a_{\theta}-a_{25}=\left(\frac{\theta-25}{15}\right) d .
$$

From this we get

$$
-\log _{10} T_{\theta}=-\log _{10} T_{25}+b d\left(\frac{\theta-25}{15}\right),
$$

as given in the certificates sent out with the issued standards. These values of $d$ are given in table 1 for the four types of standards. The assumption of linearity in the variation of $a_{\theta}$ with $\theta$ is justified by the small temperature changes involved and by the uncertainties of measurement of $d$; the values of $d$ are mostly small and are generally reported to but one significant figure.

\section{Use of Standards}

In addition to the values of transmittance at $25^{\circ} \mathrm{C}$ and the values of $d$, the Bureau reports values of uncertainty at the respective wavelengths. These uncertainties are the "huge er-

\begin{tabular}{|c|c|c|c|c|}
\hline \multirow{2}{*}{$\begin{array}{l}\text { Wave- } \\
\text { length }\end{array}$} & \multicolumn{4}{|c|}{$\begin{array}{c}\text { Temperature coefficient, } d \text {, of glasses } \\
\text { designated as- }\end{array}$} \\
\hline & $\begin{array}{l}\text { Cobalt } \\
\text { blue }\end{array}$ & $\begin{array}{l}\text { Carbon } \\
\text { yellow }\end{array}$ & $\begin{array}{l}\text { Copper } \\
\text { green }\end{array}$ & $\begin{array}{l}\text { Selenium } \\
\text { orange }\end{array}$ \\
\hline$m \mu$ & & & & \\
\hline 390 & 0.000 & -0.0005 & 0.000 & -....... \\
\hline 404. 7 & .000 & -.0025 & .000 & ...... \\
\hline 420 & ........ & -.0025 & ....... & - \\
\hline 435.8 & .000 & -.0015 & .000 & - \\
\hline 471.3 & .000 & +.001 & .000 & - . \\
\hline 491. 6 & +.0005 & - n. & - . & - \\
\hline 501.6 & +.001 & +.0035 & .000 & -..... \\
\hline 520 & +.0005 & +.0035 & - & - . \\
\hline 530 & . . . . & +. 003 & .000 & ....... \\
\hline 540 & -.003 & - & - & ....... \\
\hline 546.1 & -.004 & +.0025 & .000 & ....... \\
\hline 560 & -.003 & +.002 & .000 & ..... \\
\hline 578 & -.004 & +.0015 & -.0005 & +0.17 \\
\hline 587.6 & - & +.0015 & $\ldots$ & +.11 \\
\hline 600 & -.005 & +.001 & -.0005 & +.022 \\
\hline 620 & -.003 & +.0005 & -.001 & +.002 \\
\hline 640 & -.005 & +.0005 & -.001 & .000 \\
\hline 660 & - & .000 & - & .000 \\
\hline 667.8 & +.004 & - & -.001 & - \\
\hline 680 & +.006 & - & ...... & - \\
\hline 690 & +.004 & .000 & - & .000 \\
\hline 706.5 & +.002 & - & - & - . \\
\hline 710 & - & - & -.001 & - . \\
\hline 720 & +.0005 & -.0005 & - & .000 \\
\hline 750 & .000 & -.0005 & -.0005 & .000 \\
\hline
\end{tabular}
rors" [6], taken as 4.9 times the probable errors.
TABLE 1. Values of $d$, the temperature coefficient, for the four types of glass used as standards of spectral transmittance.

[For definition of $d$, see text.]

These huge errors have been computed twice, once in 1933 from the values obtained on the six original glasses of each type when computed to common thickness, and again in 1945-46 from values obtained from repeated determinations on the same glasses with three different types of instruments [2].

While the number of determinations entering into the computations of the huge error was too small in either case to give a highly significant result, there was satisfactory agreement in the two sets of data, and there has been no evidence that the values reported in the respective certificates do not cover the over-all uncertainty of measurement. These reported values of uncertainty are usually close to those given in figures 2 to 4 .

The method of obtaining the values of transmittance for the issued standards has varied somewhat over the years, changing with instruments 


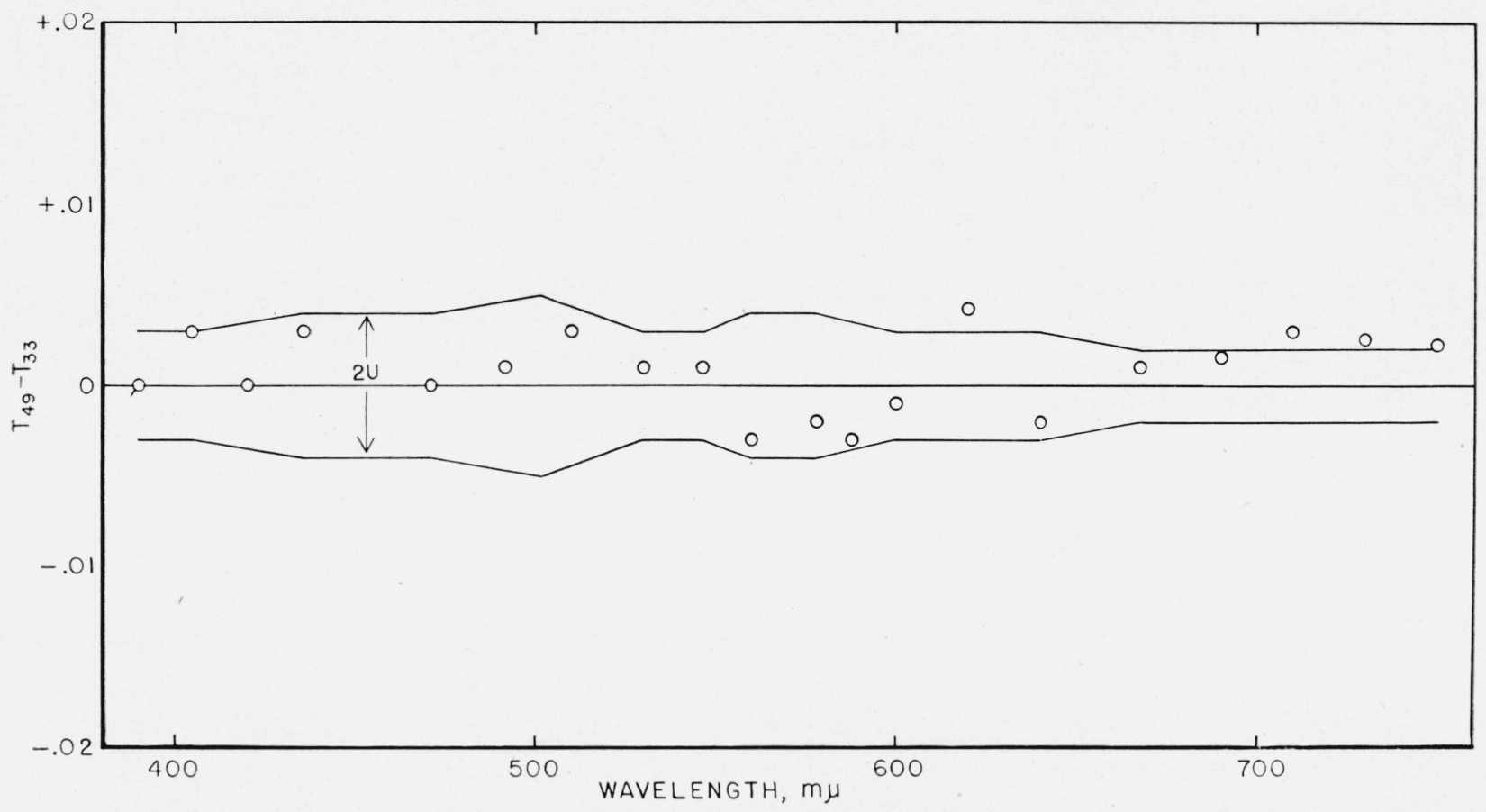

Figure 2. Permanence of a copper green glass standard kept in the Bureau files with only occasional use.

The circles represent differences between values of transmittance obtained in 1949 on the Beckman photoelectric spectrophotometer and values adopted in 1933 from measurements made on the König-Martens visual and the Gibson photoelectric spectrophotometers. The boundaries designated as $2 U$ represent the over-all uncertainties, $\pm U$, pertaining to the adopted values. It is concluded that the standard has not changed.

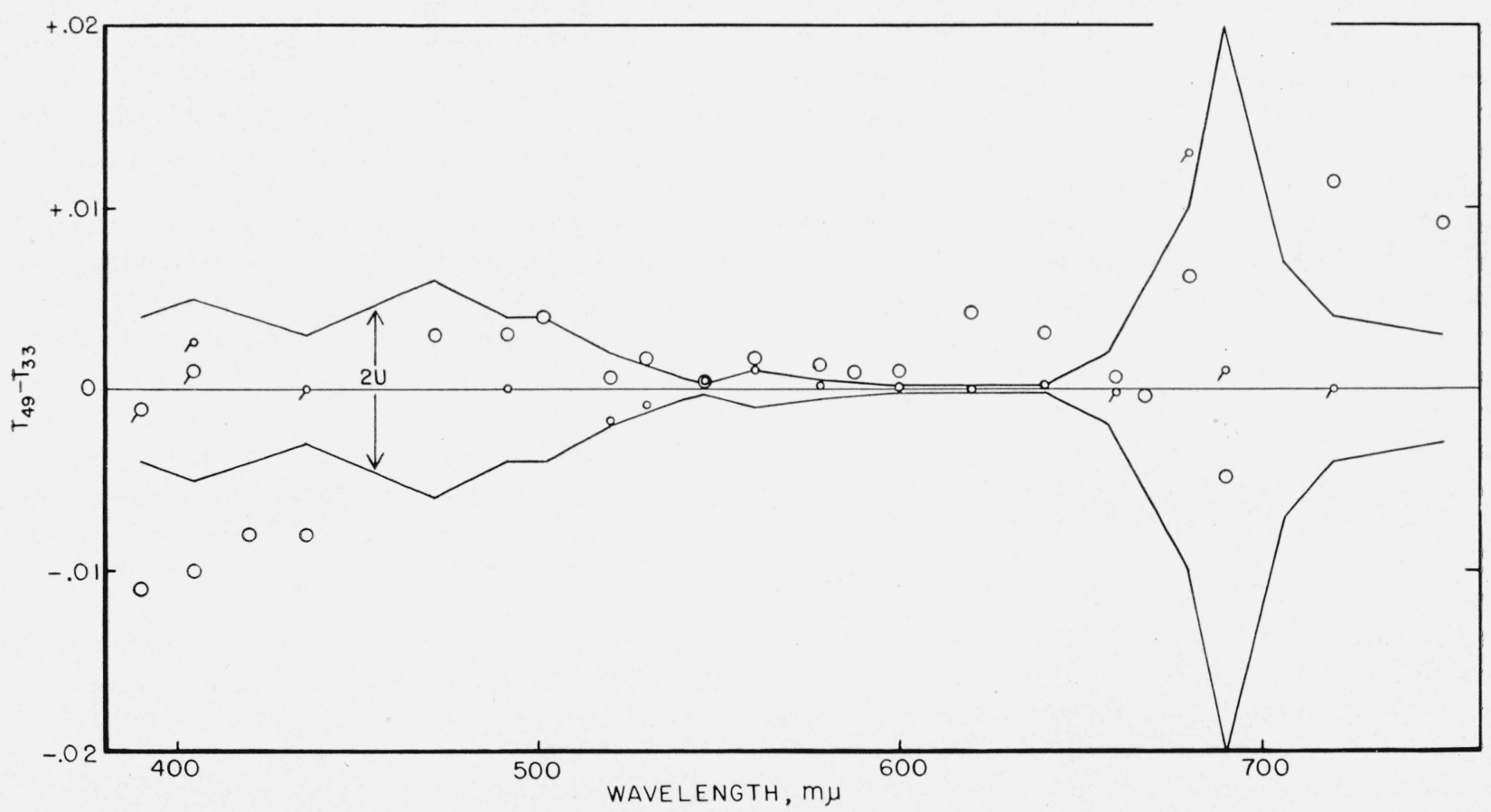

Figure 3. Permanence of a cobalt blue glass standard kept in the Bureau files with only occasional use.

The circles represent differences between values of transmittance obtained in 1949 on the Beckman photoelectric (large circles) and the König-Martens visual (small circles) spectrophotometers and values adopted in 1933 from measurements made on the König-Martens and the Gibson spectrophotometers. Circles with diagonal lines attached were obtained by use of stray energy filters in the 1949 measurements. The boundaries designated as $2 U$ represent the over-all uncertainties, $\pm U$, pertaining to the adopted values. It is concluded that the standard has not changed. 


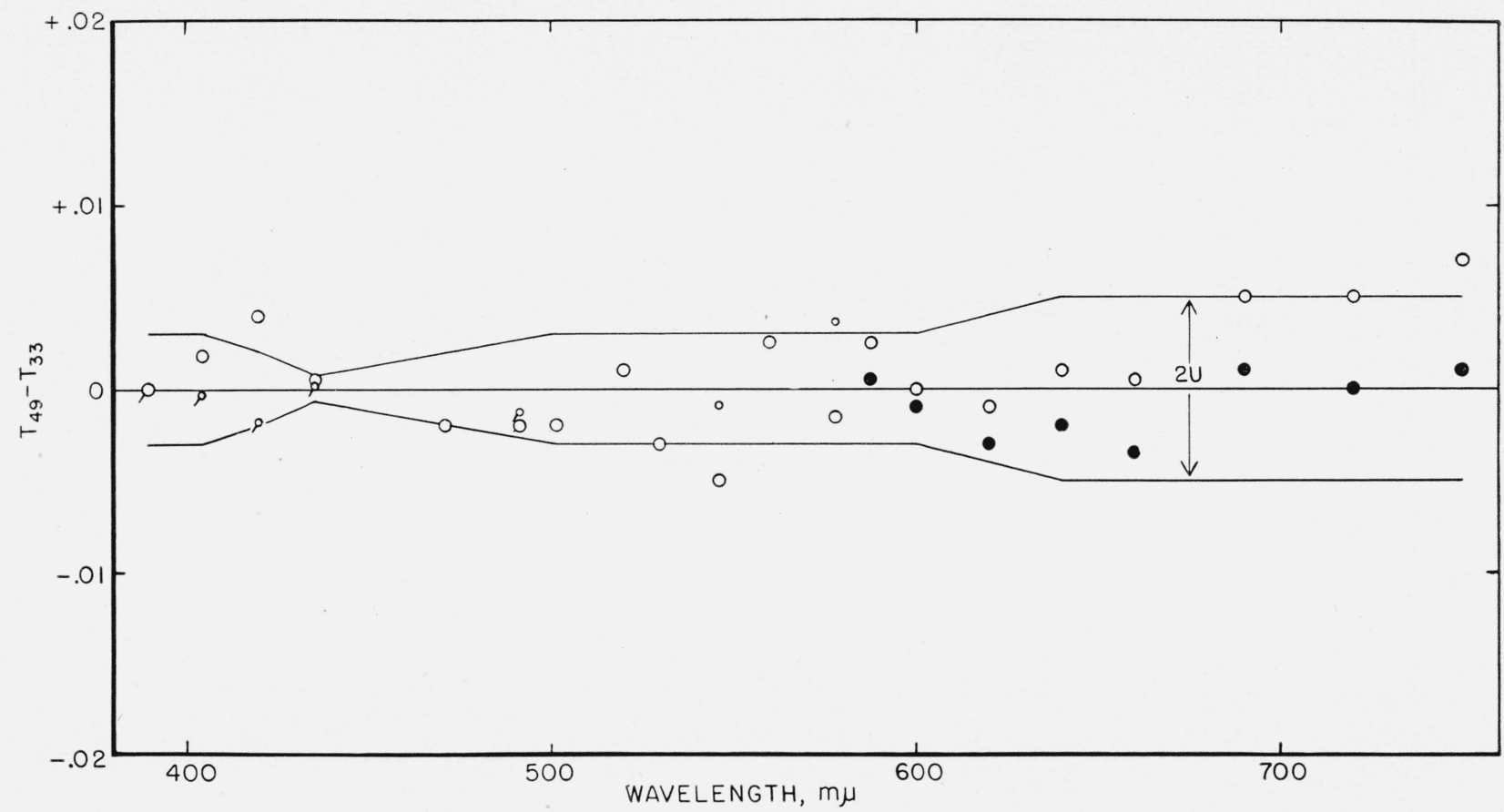

Figure 4. Permanence of a carbon yellow glass standard kept in the Bureau files with only occasional use.

The open circles represent differences between values of transmittance obtained in 1949 on the Beckman photoelectric (large circles) and the König-Martens visual (small circles) spectrophotometers and values adopted in 1933 from measurements made on the König-Martens and the Gibson spectrophotometers. The solid circles represent values of $T_{49}-T_{40}$, the adopted values having undergone slight revision in 1940 . The boundaries designated as $2 U$ represent the over-all uncertainties, $\pm U$, pertaining to the adopted values. It is concluded that the standard has not changed.

and personnel. At present the values for the issued standards are measured on the Beckman spectrophotometer $[2,7]$ by direct comparison with the carefully calibrated Bureau standards of the same type. The uncertainty of this comparison is very small, and the uncertainties as reported in the certificates are always large enough to cover this final step. In addition, an absolute determination of transmittance is usually made on each issued standard on the König-Martens visual spectrophotometer [8] at a few wavelengths, this serving continually also as an indirect check on the stability of the Bureau standards.

The intent in the use of the issued standards by those receiving them should be not to correct the photometric scale of the spectrophotometer but to check it. If the instrument gives values on the standard that are in agreement with those reported, within the combined uncertainties, the instrument presumably is functioning correctly and can be expected to give reliable results. If the values obtained are outside of the combined uncertainty, the user should attempt to eliminate the cause of the error. The issued standards are hardly adequate to use as a means of correcting the photometric scale, a possible exception to this occurring for low values of transmittance. For example, the error found by use of the standards might be caused by stray radiant energy, wide slits, or wavelength errors. If important, one should attempt to eliminate the cause, not attempt to correct the photometric scale, which may be wholly reliable.

Regarding selection of these standards by those who wish to check the photometric scale of their spectrophotometers, it is generally found that two are sufficient, (1) the carbon yellow and (2) either the cobalt blue or the copper green, depending on the desires of the user. The cobalt blue is useful for checking the photometric scale near the values $T=0.01$ or $-\log _{10} T=2.00$. The selenium orange has not proved useful for this purpose and its purchase is not recommended. Only a few have been issued.

\section{Permanence of Unexposed Samples}

The pairs of glasses originally selected for retention as Bureau standards have been kept mostly in the files, with only occasional use and 
with no excessive exposure to radiant flux. In 1933 these glasses had been carefully measured on the König-Martens visual and Gibson photoelectric [9] spectrophotometers at the various selected wavelengths from 390 to $750 \mathrm{~m} \mu$, and values of spectral transmittance adopted at that time. After the intervening 16 years, one of each of these pairs of glasses was remeasured in 1949, and the comparison of these results with those adopted in 1933 is given in this section.

The glasses selected for this comparison are designated as Corning G55A $\alpha^{11}$ (cobalt blue), Corning HT Yellow $\alpha^{7}$ (carbon yellow), and Jena BG $14^{1}$ (copper green). The spectral transmittances of these glasses are shown in figure 1 (the upper of the two light-weight curves in each case). (As noted above, the Jena OG3 glasses have proved to have little use as spectrophotometric standards, and no investigation of their permanence has been made.) The most certain test of permanence would have been to remeasure these glasses on the same instruments and under the same instrumental conditions as were used in the original measurements. The older methods are slower, however, particularly the visual, and in the hopes of expediting the work the three samples were measured on the more rapid Beckman spectrophotometer. These measurements were on an absolute basis, not relative to any other standard, and were made with the samples at $25^{\circ} \mathrm{C}$ as in the previous measurements. They did, in fact, show that the samples had in all probability not changed, but it proved necessary also to make some additional measurements on the KönigMartens for greater certainty, particularly at the low transmittances.

The results could be illustrated in various ways, but the most suitable appears to be that used in figures 2,3 , and 4 . In these figures there are shown the differences between the values of spectral transmittance measured on the Beckman or König-Martens spectrophotometers in 1949, and as adopted in 1933 from the measurements made on the König-Martens and Gibson spectrophotometers. These differences are designated as $T_{49}-T_{33}$ and are plotted as circles. In the same figures there are shown the over-all uncertainties, $\pm U$, that are usually reported on the issued standards and that would apply closely to the adopted values. If the 1949 values fall within these uncertainties there would be no certainty of change in the transmittance having occurred. Furthermore, at least an equal over-all uncertainty should be assumed for the 1949 values, so that deviations up to twice the plotted uncertainties would not give certain indications of change.

As may be seen, the values of $T_{49}-T_{33}$ in most cases fall within the over-all uncertainties plotted. In those instances where the values fall outside, the evidence, such as it is, is nullified by the other measurements shown.

With special reference to figure 4, Corning HT Yellow $\alpha^{7}$, the values adopted in 1933 were revised slightly in 1940 at the longer wavelengths on the basis of some measurements made at that time, and in figure 4 the values of $T_{49}-T_{40}$ are also shown. It is not believed that the sample changed between 1933 and 1940, but it was felt in 1940 that the revised values were slightly more accurate than the 1933 values. Note, however, that the values of $T_{49}-T_{33}$ exceed the uncertainties only at $750 \mathrm{~m} \mu$.

It seems fair to conclude that the spectral transmittances of these standards have not changed over this 16-year period.

\section{Accelerated Exposure Tests}

It was desired that the accelerated exposures should be made under conditions not too widely different from ordinary indoor conditions. The samples were accordingly placed in a small box with a plate glass cover, which was kept outside of a south window on the fourth floor. The samples were thus exposed to daylight, including sunlight, from the south half of the sky, in all kinds of weather. However, the plate glass and box kept the samples dry at all times. The plate glass further served to keep the solar ultraviolet radiant flux of the shortest wavelengths from the glasses, since conditions would otherwise not have been comparable with those indoors. Small holes in the box permitted circulation of air in and out of the box and helped to prevent condensation of moisture on the plate glass cover.

These exposure tests were made with carbon yellow, copper green, and cobalt blue glasses similar to the respective standards. No corresponding tests have been made of the selenium orange glass. Measurements on the three glasses were made prior to the start of the exposures and further measurements have been made after the 


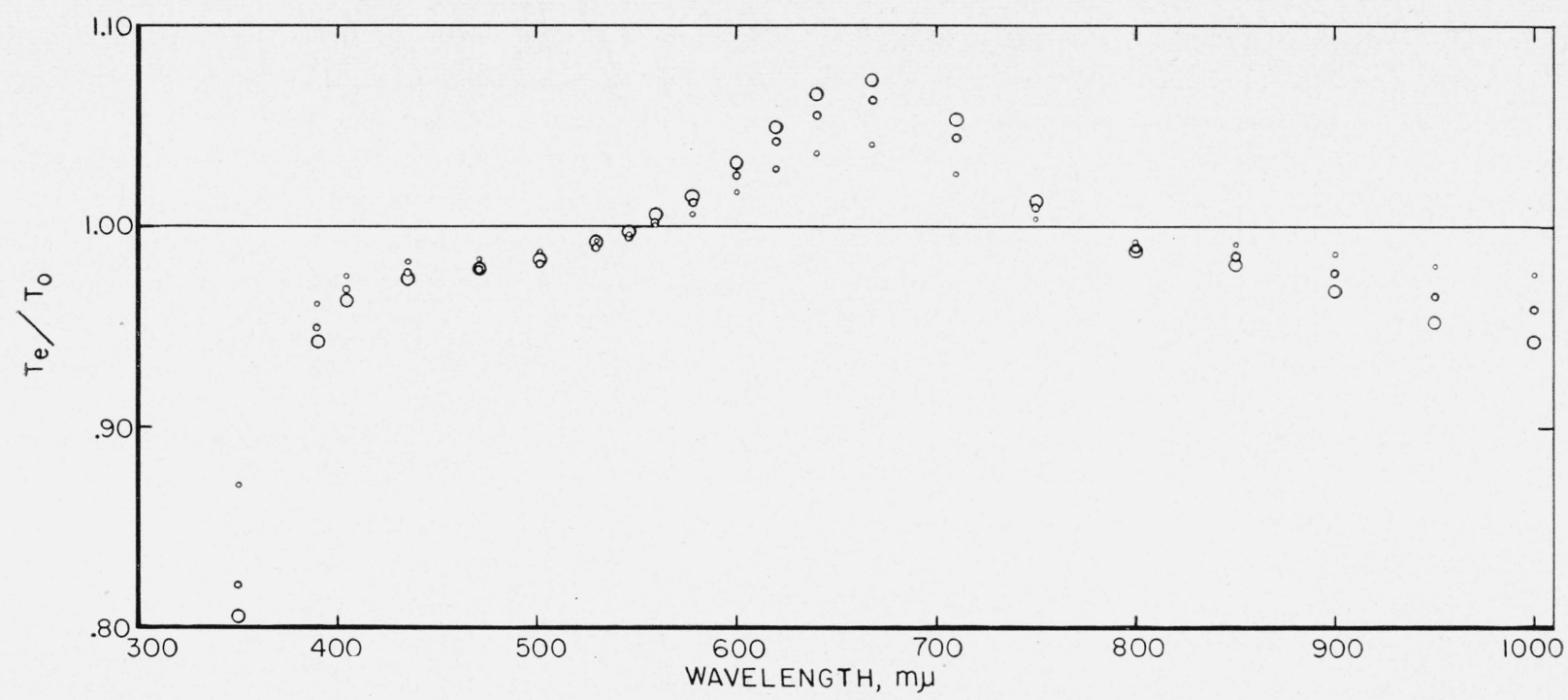

FIGURE 5. Change of spectral transmittance of a copper green glass (similar to the standards) upon exposure under glass to south skylight (including sunlight).

$T_{0} / T_{0}$ is the ratio between the transmittance after exposure $\left(T_{\theta}\right)$ and the transmittance before exposure ( $\left.T_{0}\right)$. The small circles are for an exposure of 3 months, the intermediate circles for 1 year, 8 months, and the large circles for 2 years, 8 months. At $334.2 \mathrm{~m} \mu$ the respective ratios are $0.39,0.25$, and 0.21 .

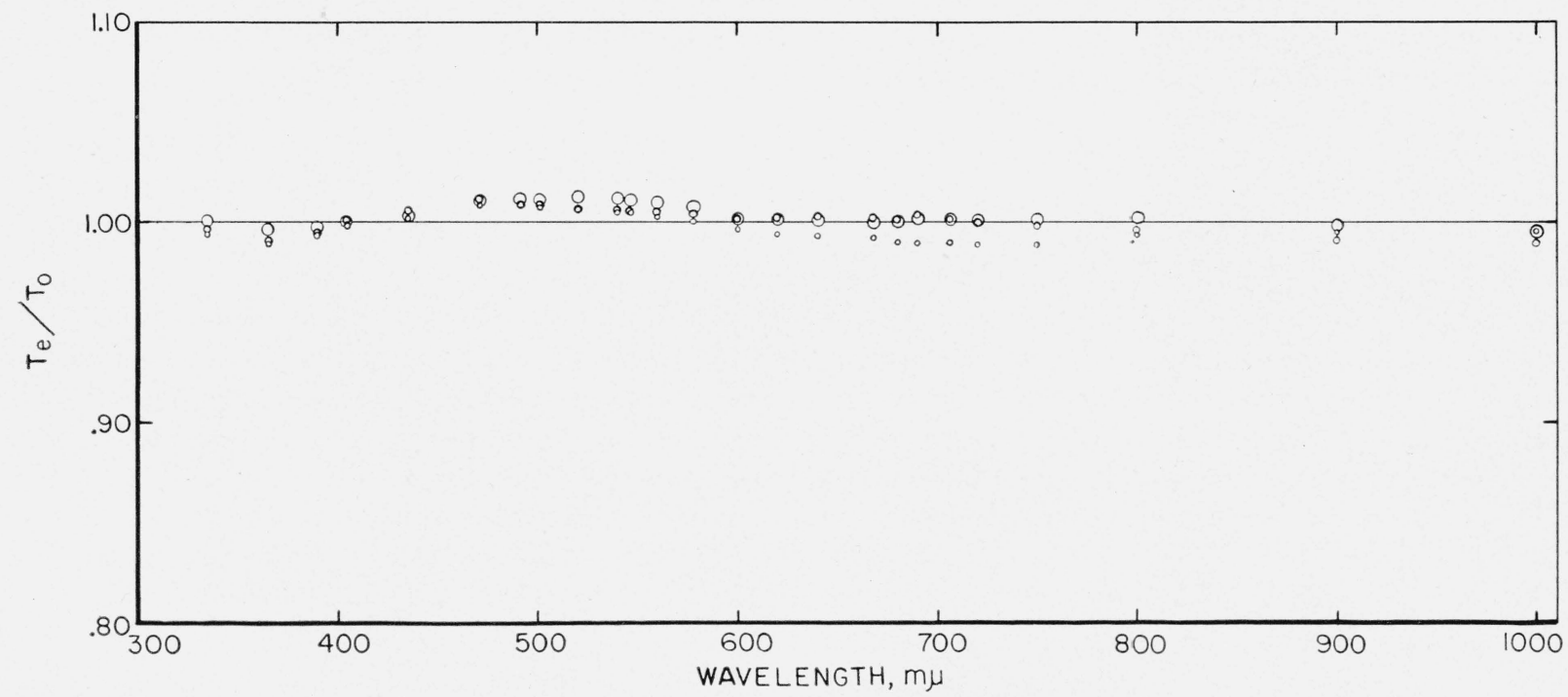

FIGURE 6. Change of spectral transmittance of a cobalt blue glass (similar to the standards) upon exposure under glass to south skylight (including sunlight).

$T_{e} / T_{o}$ is the ratio between the transmittance after exposure $\left(T_{\boldsymbol{c}}\right)$ and the transmittance before exposure ( $\left.T_{\boldsymbol{o}}\right)$. The small circles are for an exposure of 3 months, the intermediate circles for 1 year, 8 months, and the large circles for 2 years, 8 months. The "changes" barely exceed the uncertainties of measurement.

periods indicated. All measurements were made at $25^{\circ} \mathrm{C}$.

The results are illustrated in figures 5,6 , and 7 . Differing from figures 2 to 4 , the ordinates of these figures are plotted as ratios rather than differences. These ratios are the values of transmittance measured after the indicated exposures divided by the respective values of transmittance before the exposures began. Since all of these measurements, initial and after exposure, were made on the Beckman spectrophotometer relative to a closely similar reference glass, the precision of measurement was higher than obtainable in figures 2 to 4 , in which the measurements were 


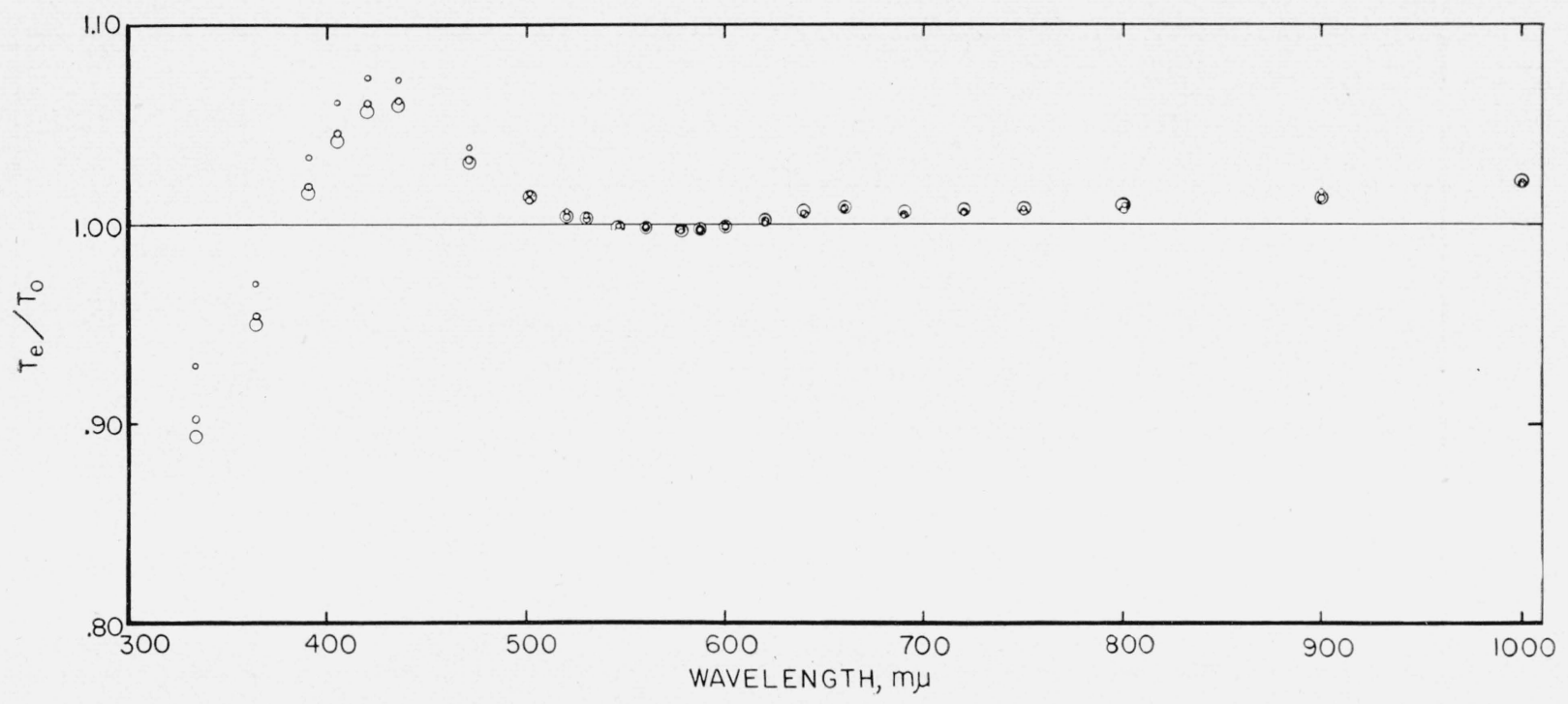

FIGURE 7. Change of spectral transmittance of a carbon yellow glass (similar to the standards) upon exposure under glass to south skylight (including sunlight).

$T_{e} / T_{o}$ is the ratio between the transmittance after exposure $\left(T_{\bullet}\right)$ and the transmittance before exposure ( $T_{o}^{*}$ ). The small circles are for an exposure of 3 months, the intermediate circles for 1 year, 8 months, and the large circles for 2 years, 8 months. Note that between 400 and $500 \mathrm{~m} \mu$ the values of $T_{e} / T_{\bullet}$ are greatest for the shortest exposure.

made on an absolute basis, no reference standard being involved.

It is probable that all changes indicated in figures 5 to 7 outside the value $1.00 \pm 0.01$ are certain, and in fact the consistency of the data in some cases indicates that the changes are real even though less than 1 percent. $^{3}$

Perhaps the most important conclusion to be drawn from figures 5 to 7 is that, in view of the small changes that occurred between 390 and $750 \mathrm{~m} \mu$, the wavelength range for which the issued standards are customarily certified, one would not expect the issued standards to show changes with ordinary laboratory use. In this respect the data of figures 2 to 4 and 5 to 7 may be said to be consistent, and thus the assumption made, or perhaps we should say the result hoped for, in 1933 has been corroborated.

A few details relating to figures 5 to 7 may be noted.

1. In the ultraviolet between 334.2 and $400 \mathrm{~m} \mu$

3 It may be noted that the ratios shown in figures 5 to 7 must be multiplied at each wavelength by the respective values of transmittance shown in figure 1 to obtain values of $\Delta T$ comparable with those shown in figures 2 to 4 . For example, in figure 5 at $680 \mathrm{~m} \mu$ the ratio, $T_{0} / T_{0}$, for 3 months exposure is 1.041 . From figure $1, T_{0}=0.115$ (for a different sample of the same type). $T_{0}-T_{0}=$ $\left(T_{e} / T_{0}\right) T_{0}-T_{0}=1.041 \times 0.115-0.115=0.120-0.115=0.005$. From figure 2 the value of $\Delta T$ at $680 \mathrm{~m} \mu= \pm 0.002$. That is, after 3 months of exposure, the change produced is only $2 \frac{1}{2}$ times the uncertainty in absolute measurement shown in figure 2. A further illustration is given later in this paper for the carbon yellow glass. the copper green glass, figure 5, shows a large solarization effect of the usual type, the carbon yellow glass, figure 7 , a small one, and the cobalt blue glass, figure 6, none at all. It is possible, of course, that the cobalt blue glass might solarize at shorter wavelengths. Those interested in this effect should read the papers by Coblentz and Stair, who made an extensive study of the ultraviolet solarization of window glasses and other materials $[10,11]$.

2. The changes in the cobalt-blue glass, figure 6 , are small throughout, with extremes barely exceeding 1 percent. While some of the changes shown are probably real, further work would be necessary to indicate whether the rather erratic behavior shown by the curves are significant. The changes, if real, are certainly not important for this purpose, and no further measurements are contemplated.

3. The changes in the copper green glass shown by the curves of figure 5 are undoubtedly real, but again are of little importance (above $390 \mathrm{~m} \mu$ ) in view of the extent of the exposure necessary to bring them about.

4. The major changes shown by the carbon yellow glass of figure 7 are also undoubtedly real. Again these would not be judged of much importance in this connection except for the fact 


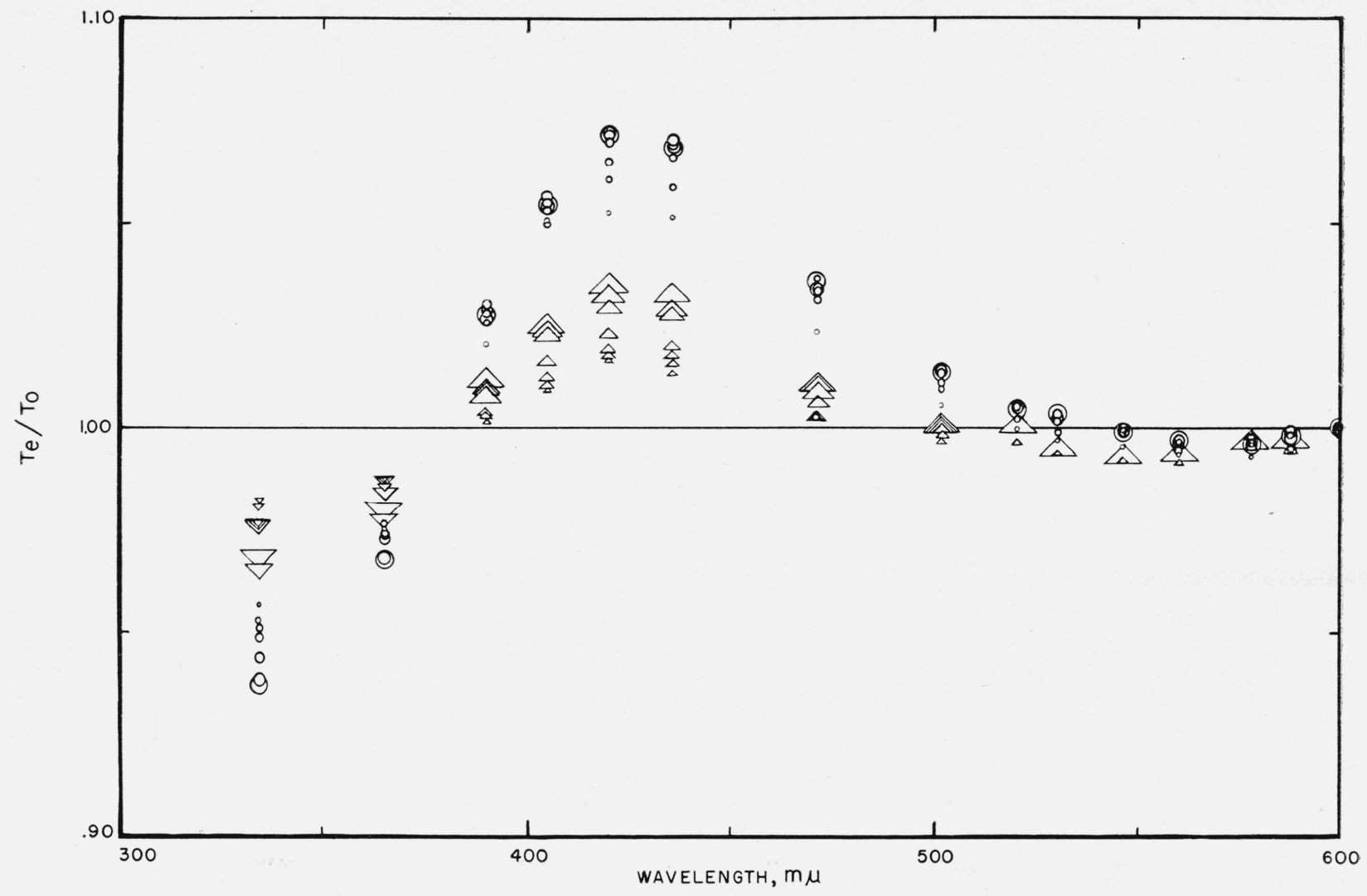

FIGURE 8. A repetition of figure 7 over the range from 300 to $600 \mathrm{m \mu}$, with other similar carbon yellow glasses and shorter exposures.

Small to large circles represent exposures of $10,17,27,32,38,45$, and 53 days. Small to large triangles represent exposures of $1,2,3,4,5,6$, and 7 days. Note that below $500 \mathrm{~m} \mu$ there is a definite change upon exposure to sunlight of only one day.

that all of the change occurred during the first summer of exposure, there being in fact a slight recovery shown by the later measurements. Another sample was accordingly selected and measurements made at the intervals shown in figure 8. These results show that the large change between 400 and $500 \mathrm{~m} \mu$ starts immediately upon exposure and is half completed within 8 days after start of the exposure. One would therefore recommend that this glass not be left around where sunlight or other strong radiant flux might irradiate it. At that, however, only at $435.8 \mathrm{~m} \mu$ do the changes shown in figures 7 and 8 greatly exceed the over-all uncertainties shown in figure $4 .^{4}$

\footnotetext{
${ }^{4}$ This is shown by three examples: (1) The transmittance of this glass at $435.8=0.040$. $1.07 \times 0.040=0.0428$. $0.0428-0.040=0.0028$, which is four times the tolerance shown in figure 4 at $435.8 \mathrm{~m} \mu$. (2) At $420 \mathrm{~m} \mu T=0.035$ and the resulting change in $T=0.0025$ compared with an uncertainty of 0.002 in figure 4. (3) At $501.6 \mathrm{~m} \mu T=0.254$ and the resulting change in $T=0.004$, compared with an uncertainty of 0.003 in figure 4 .
}

Acknowledgment is made to various individuals who have cooperated in this work. Most of the original measurements were made by Geraldine Walker Haupt and Mabel E. Brown, as indicated by reference [1]. Recordings of the spectral transmittances of the standards were made at various times by Harry J. Keegan. Recent calibrations of new standards of the same type of glass were made by Margaret M. Balcom and Lois Peterson Gloster, as indicated in reference [2]. Miss Peterson also made new and more precise determinations of the change of transmittance with temperature than had been possible with the previous instruments, and made the initial measurements on the exposure tests.

\section{References}

[1] K. S. Gibson, G. K. Walker, and M. E. Brown, Filters for testing the reliability of spectrophotometers, J. Opt. Soc. Am. 24, 58 (1934). 
[2] K. S. Gibson and M. M. Balcom, Transmission measurements with the Beckman quartz spectrophotometer, J. Research NBS 38, 601 (1947) RP1798; J. Opt. Soc. Am. 3\%, 593 (1947).

[3] Standards for checking the calibration of spectrophotometers, NBS Letter Circular, LC929 (1948).

[4] K. S. Gibson, Spectrophotometry (200 to 1,000 millimicrons), NBS Circular C484 (1949).

[5] Terminology and symbols for use in ultraviolet, visible, and infrared absorptometry. NBS Letter Circular, LC857 (1947).

[6] M. Merriman, A textbook on the method of least squares, 8th ed., rev. (John Wiley \& Sons, Inc., New York, N. Y., 1911).

[7] H. H. Cary and A. O. Beckman, A quartz photoelectric spectrophotometer, J. Opt. Soc. Am. 31, 682 (1941).
[8] H. J. MeNicholas, Equipment for routine spectral transmission and reflection measurements, BS J. Research 1, 793 (1928) RP30.

[9] K. S. Gibson, Direct-reading photoelectric measurement of spectral transmission, J. Opt. Soc. Am. \& Rev. Sci. Instr. 7, 693 (1923).

[10] W. W. Coblentz and R. Stair, Data on ultraviolet solar radiation and the solarization of window materials, BS J. Research 3, 629 (1929) RP113.

[11] W. W. Coblentz and R. Stair, Ultraviolet transmission changes in glass as a function of the wavelength of the radiation stimulus, J. Research NBS 13, 773 (1934) RP744.

Washington, December 20, 1949. 